\section{Nature of the Olefines produced by Apples}

Since Gane ${ }^{1}$ identified ethylene as a volatile product of ripening apples, other workers $^{2-4}$ have demonstrated its production by other fruits, leaves and the fungus Penicillium digitatum. The identification by conversion to ethylene dibromide and then to the crystalline substance $\mathrm{NN}^{\prime}$-diphenylethylenediamine established ethylene as the predominant olefine, but did not specifically exclude higher homologues the derivatives of which could be lost during crystallization of the main product. As the volatile emanations of apples include a series of acids and alcohols with one to six carbon atoms ${ }^{5-7}$, the absence of a corresponding series in the olefines cannot be accepted without rigorous proof.

Ethylene given off by Granny Smith apples at $5^{\circ} \mathrm{C}$. was absorbed in an ice-cooled $0.25 M$ solution of mercuric perchlorate in $2 M$ perchloric acid ${ }^{8}$. The ethylene was regenerated with lithium chloride and collected over a saturated lithium chloride solution. After removal of polar substances by successive treatments with sodium bisulphite, sodium hydroxide and calcium chloride solutions, the ethylene was submitted to mass spectrometric analysis. The sample was found free of higher olefines, the limit of detection being 0.1 per cent of the ethylene. Afterwards, another sample of ethylene was collected from apples at room temperature $\left(18-22^{\circ} \mathrm{C}\right.$.), and the same result obtained. From an artificial mixture of ethylene (97 per cent), propylene (2 per cent) and 1-hexane (1 per cent) subjected to the above procedure, threequarters of the propylene was recovered but only one-fifth of the l-hexene. The absence of propylene within the limit of detection was established, but the presence of significant amounts of other olefines was left in doubt.

Further tests were made by gas chromatography. The ethylene produced by apples at $12-18^{\circ} \mathrm{C}$. was absorbed and liberated as before, but further chemical treatment was found necessary, as polar substances were relatively retarded on a tricresyl phosphate column and did not interfere with the detection of olefines up to hexene. When 10-20 ml. of ethylene from apples was introduced into the carrier gas, a large ethylene peak occurred about 20 sec. later. The base-line then became perfectly stable with no subsequent peaks for a total period of $30 \mathrm{~min}$. The analysis was carried out at $20^{\circ} \mathrm{C}$. on a $1-\mathrm{m}$. column of $6 \mathrm{~mm}$. cross-section, composed of 20 per cent tricresyl phosphate on 40-60 mesh $C .22$ firebrick. Nitrogen as carrier gas at a rate of flow of $40 \mathrm{ml} . / \mathrm{min}$. and a thermal conductivity detector were used. When propylene was added to pure ethylene, it was completely recovered after absorption and liberation, and could be detected in a concentration of 0.1 per cent by volume. The propylene peak occurred at 1 min. 1-Hexene mixed with ethylene at a partial pressure of 1 per cent was absorbed and held for 4 days at $0^{\circ} \mathrm{C}$. to simulate the collection period of the apple ethylene. The regenerated gas gave a hexene peak at $15 \mathrm{~min}$. which indicated more than 90 per cent recovery and was at least ten times the limit of detection. Hence 0.1 per cent of 1-hexene would have been detected in the apple ethylene. Tests with 2 -pentene gave only 20 per cent recovery, but still gave a peak at $7 \frac{1}{2} \mathrm{~min}$. which indicated that about 0.2 per cent could be detected in apple ethylene.
It seems reasonably established that normal olefines from propylene to hexene cannot be present in proportions which exceed one part of higher olefine to 1,000 parts of ethylene. All unsaturated hydrocarbons cannot be excluded, as those with branched chains or more than one double bond may be more labile and hence not regenerated with the ethylene. Gas chromatography of a low-temperature condensate gave no evidence of saturated hydrocarbons.

These results raise afresh the problem of the biogenesis of ethylene in relation to other aspects of plant metabolism. Either the precursor is as free from homologues as the ethylene itself, or the ethylene-producing system is sufficiently specific to exclude them.

We are indebted to Dr. J. D. Morrison and Dr. F. Dorman, Commonwealth Scientific and Industrial Research Organization, Division of Chemical Physics, for mass spectrometric analysis.

\section{F. E. HUELIN \\ B. H. KENNETT}

Division of Food Preservation,

Commonwealth Scientific and

Industrial Research Organization,

Homebush, New South Wales.

1 Gane, R., J. Pom. Hort. Sci., 13, 351 (1935). 29, 168 (1954).

- Young, R. E., Pratt, H. K., and Biale, J. B., Plant Physiol., 26, 304 $(1951)$.

Thompson, A. R., Austral. J. Sci. Res., B, 4, 283 (1951)

Henze, R. E., Baker, C. E., and Quackenbush, F. W., Proc. Amer. Soe. Hort. Sci., 61, 237 (1953).

- Meigh, D. F., J. Sci. Food Agric., 8, 313 (1957).

Young, R. E., Pratt, H. K., and Biale, J. B., Anal. Chem., 24, 551 (1952).

\section{Cell-Wall Formation in Root Hairs}

Electron microscopic studies of the cell-wall organization in root hairs have shown that the microfibrils of the cellulose framework have a random orientation on the outer surface ${ }^{1,2}$ of the cell but on the inner surface they have an axial orientation $^{2}$. This inner axially oriented layer was considered by Roelofsen ${ }^{2}$ to be secondary thickening. In view of the extensive evidence $\theta^{3,4}$ of the extremely localized tip growth of root hairs, the growth of these cells has been examined in recent work in this laboratory to assist in interpreting results relating to autoradiographic studies of growth of cells in which localized growth may take place. In the course of this work autoradiographs have been prepared of root hairs grown in solutions of glucose labelled with carbon-14 under varying conditions. Oat seeds were germinated on wet filter paper and then immersed in a solution containing $10 \mu \mathrm{c}$. of labelled glucose in $5 \mathrm{ml}$; (the total glucose concentration being adjusted to 1 per cent with unlabelled glucose) under the following conditions: $(a)$ Continuous immersion in the labelled glucose solution; (b) $16 \mathrm{hr}$. in labelled glucose and $36 \mathrm{hr}$. in unlabelled glucose (1 per cent); (c) $36 \mathrm{hr}$. in unlabelled glucose followed by $31 \mathrm{hr}$. in labelled glucose.

After these treatments the root hairs were extracted by six alternate treatments with $0 \cdot 1 M$ hydro. chloric acid and $0.1 M$ sodium hydroxide and auto- 